\title{
A MORTE, O LUTO E A MEMÓRIA: POSSIBILIDADE DE COMPREENSÃO SOCIO- CULTURAL E HISTÓRICA
}

\section{THE DEATH, THE MOURNING AND THE MEMORY: POSSI- BILITY OF A HISTORIC AND SOCIOCULTURAL UNDER- STANDING}

Yan Bezerra de Morais $^{1}$

Resumo: Como a relação entre morte, luto e memória pode proporcionar meios de compreensão de aspectos socioculturais e históricos? Este artigo é parte das discussões de uma monografia em construção, e tem por objetivo contribuir com as atuais discussões e pesquisas ao apresentar algumas considerações historiográficas a partir de uma revisão de literatura que trata da morte e do luto, e suas características no percurso histórico, e que através da memória se tornam fontes de estudo social e cultural da experiência humana. A memória, desta forma, é o ponto de interseção entre os aspectos socioculturais que envolvem a morte, uma vez que é partir dos meios utilizados pelos indivíduos, grupos familiares ou comunidades para manter a lembrança sobre o ente que se foi, sobre as causas da morte e sobre a lida com essa morte, que o historiador ganha uma nova possibilidade de objeto de estudo.

Palavras-chave: Morte; Luto; Memória; Cariri cearense.

Abstract: How the relation among death, mourning and memory may provide means to understand sociocultural and historic aspects? This article is part of discussions of a monograph in progress and aims to

\footnotetext{
${ }^{1}$ Graduando em História. Bolsista do Programa de Iniciação Científica do Conselho Nacional de Desenvolvimento Científico e Tecnológico - CNPq. Universidade Federal de Campina Grande - Campus Cajazeiras. Unidade Acadêmica de Ciências Sociais. E-mail: <yanbmorais@hotmail.com>. Orientado pela Prof. $^{a}$ Viviane Gomes de Ceballos. Mestre e Doutoranda em História Social pela Unicamp. Docente do Curso de História. Universidade Federal de Campina Grande - Campus Cajazeiras. E-mail: <vgceballos@gmail.com>.
} 
contribute to current discussions and research while presents some historiographical considerations from a review of literature that deals with death and grief and their characteristics in the historical course, and through memory that become sources of social and cultural study of human experience. Memory, therefore, is the point of intersection between the social and cultural aspects involving death, since it is based on the methods used by individuals, family groups or communities to keep the memory of the one who passed away, on the causes of death and the dealing with this death, the historian gains a new possibility of study's object.

Keywords: Death; Mourning; Memory.

\section{Levantando questionamentos}

Ao assistir o documentário "Um corpo subterrâneo" (2007) de Douglas Machado, onde o ponto chave é a morte e a relação dos vivos com a morte do outro, despertou-se um questionamento acerca do porquê a morte ter a capacidade de modificar radicalmente as emoções humanas se ela é algo que nunca deixou de existir e nunca o irá, e o porquê de os vivos buscarem tanto não esquecer a pessoa que morreu como se o esquecimento viesse a ser um desrespeito com o morto. Para compreender o que é a morte e o que ela causa nos que ficam, achamos conveniente refletir acerca dos estudos desenvolvidos por Philippe Ariès (2003), Júlio José Chiavenato (1998), José Luiz de Souza Maranhão (1992), Colin Murray Parkes (1998), entre outros autores que discutem em seus trabalhos os conceitos-chave deste texto: a morte, o luto, a memória, e a relação e articulação entre eles.

Seguindo as discussões destes, a proposta para a pesquisa a ser realizada é utilizar a memória, através da história oral, além das fontes 
cartoriais e das fontes imagéticas, para se constituir uma colcha de retalhos, formada pela experiência individual de cada pessoa a ser entrevistada e do grupo a que pertencem, para assim, conseguirmos nos aproximar de uma compreensão sociocultural e histórica do Cariri cearense.

A escolha do recorte temporal para a pesquisa monográfica partiu de um levantamento realizado no I Cartório de Registro da cidade de Barro, localizada no Cariri cearense ${ }^{2}$, onde o número de mortes mostrou-se alto entre os anos 1950 e 1959, principalmente em relação ao número de morte de crianças, sendo $73 \%$ do total de mortes no período. Levando assim à formulação da problemática, partindo de certos questionamentos, como: qual seria o peso da fatalidade e do econômico na causa da morte em Barro na década de 1950? Há relação entre ambos? Qual a condição socioeconômica das famílias? Houve auxílio governamental? Qual o relacionamento do sertanejo com a morte? É uma tragédia ou a libertação do sofrimento? Quais mudanças ocorreram na vida cotidiana da família com a morte do ente? O que foi feito para que se mantivessem vivas as memórias sobre este ente? Qual era o tipo de luto frequente em Barro na década de 1950? O tipo de luto tem relação direta com a percepção que se tem da morte? Estes questionamentos fazem parte da possibilidade de compreensão sociocultural e histórica que propomos para a pesquisa monográfica e que discutiremos enquanto real possibilidade no decorrer deste texto.

\footnotetext{
${ }^{2}$ Microrregião cearense, localizada no sul do Estado, zona semiárida, com distância em torno500 km da capital Fortaleza. A região abrange 28 municípios no total (Brasil - Ministério do Desenvolvimento Agrário, 2010).
} 
Com este artigo, então, pretendemos contribuir com as atuais discussões e pesquisas com problemáticas semelhantes à nossa ao apresentar e discutir algumas considerações historiográficas a partir de uma revisão de literatura acerca da morte e do luto, que através da memória se tornam fontes de estudo social e cultural na ciência histórica. Não pretendemos aqui, apresentar resultados de nossa pesquisa, mas algumas de nossas propostas sustentadas pelo arcabouço teórico que vem servindo de base para este trabalho em construção.

\section{A morte e o luto: dimensões socioculturais e históricas}

É que da bem-aventurança e da alegria na vida há pouco a ser dito enquanto duram; assim como as obras belas e maravilhosas, enquanto perduram para que os olhos as contemplem, são registros de si mesmas; e somente quando correm perigo ou são destruídas é que se transformam em poesia (TOLKIEN, 2009, p. 110).

A noção e percepção sobre a morte é apresentada por Philipe Ariès (2003) como algo que vem mudando no decorrer dos séculos, mais especificamente entre os séculos $\mathrm{X}$ e $\mathrm{XX}$, com suas mudanças de foco que passam desde a morte do eu à morte do outro. A morte do eu, isto é, a própria morte, o próprio adeus à vida terrena, foi por muitos séculos, durante o período estudado por Ariès (2003), o foco do homem ocidental quando se pensava a morte. Desde o século XVIII, a morte do outro é a que passa a ser vista como desgraça, como algo que atinge não somente quem vai, mas também quem fica, acentuando-se após a I e II 
Guerras Mundiais no século XX e a massificação da morte, isolando-a do cotidiano como tentativa de amenização. Assim como a morte, o luto torna-se questão relevante para esse autor, desde o luto ritualizado ao luto exacerbado e sem regras que também é mostrado por Chiavenato (1998) e que serão discutidos em momento mais oportuno neste texto.

Nos últimos séculos da Idade Média, a visão que se tinha sobre a morte difere das visões modernas por considerá-la parcela inerente à vida. A morte era domesticada, era algo comum à vida cotidiana do homem medieval, provavelmente pelo fato do sentimento de comunidade ser muito forte e as pessoas estarem sempre muito próximas (noção de individualidade e privacidade em desenvolvimento ${ }^{3}$ ). Assim também a alta frequência da morte causada por epidemias, guerras ou outros fatores, levava a morte do outro ao patamar abaixo da morte do eu, pois como afirma Luizetto (1989), neste período de crises que foi o fim da Idade Média, a preocupação estava voltada para o eu, tanto em termos físicos como espirituais.

Desde fins do século XIX e início do século XX nas sociedades industriais, a morte substituiu o sexo no patamar dos maiores tabus, pois a morte se tornou algo externo, não mais como parte do cotidiano e normal à vida, evidenciando mudanças do homem ocidental em relação à morte (ARIÈS, 2003; CHIAVENATO, 1998; MARANHÃO, 1992).

\footnotetext{
${ }^{3}$ Cf. Ariès, Philippe. Por uma História da vida privada. In: Chartier, Roger (Orgs.). História da Vida Privada 3: da Renascença ao Século das Luzes, 1986, p. 7-20.
} 
Ariès (2003) mostra que as atitudes tradicionais diante do tema morte continuaram as mesmas nos países predominantemente rurais e católicos, como é o caso do Brasil até meados do século XX, e, uma vez que o sexo continuava como o maior tabu, a morte poderia não ser externa à vida. Essa perspectiva é a mais viável para entender a morte no sertão cearense, que até pelo menos a década de 1980 foi predominantemente rural, e somente na década de 1990 é marcado pela industrialização como apontam Feitosa, Queiroz e Cordeiro Neto (2009) ao estudarem o processo de industrialização do "centro" da microrregião cearense chamada Cariri, o "triângulo Crajubar".

Então, o Cariri cearense de meados do século XX era puramente rural como Ariès (2003) propõe de modo geral, e o sexo o maior tabu, como afirmam as pessoas mais idosas da $\operatorname{cidade}^{5}$; a morte, que por ser frequente àquela época devido a fatores diversos como a seca e a condição socioeconômica do sertanejo nos leva a levantar a hipótese de que ela não foi "excluída da vida" como em sociedades industriais.

Maranhão (1992) ao pesquisar a percepção, o trato e as dimensões socioculturais e econômicas da morte em seu livro "O que é morte", mostra uma possibilidade de compreensão do significado da morte no Cariri cearense ao evidenciar a alta mortalidade nordestina em meados do século XX e afirmar que o sertanejo detém, de certa forma, uma afeição pela morte como libertadora do sofrimento, pois a vida não lhes

\footnotetext{
${ }^{4}$ Triângulo Crajubar se refere às três principais cidades do Cariri cearense: Crato, Juazeiro do Norte e Barbalha.

${ }^{5}$ Isto pôde ser percebido através de conversas informais com idosos, durante um diagnóstico prévio acerca do tema.
} 
pertence, pertence ao trabalho e à busca pela sobrevivência, apenas a morte pode ser sua propriedade, ao contrário das riquezas e qualidade de vida.

Frente a isso, a condição socioeconômica se mostra relevante, pois tanto Maranhão (1992) quanto Chiavenato (1998) mostram que essa condição proporciona meios de se compreender os modos de trato com a morte. $\mathrm{O}$ fator socioeconômico também é para os autores um dos principais pontos ao se pesquisar sobre a desigualdade dos homens frente à morte, seja desigualdade tanto no próprio ato de morrer (causas), quanto no lidar com a morte do outro (percepção e memória). A essa condição material, acrescenta-se ainda o fator cultural, o qual, segundo Chiavenato (1998), sempre será a principal via de se explicar a atitude do homem diante da morte.

Segundo Maranhão (1992), o fator econômico é, sim, um forte agravante da situação nordestina, pois ele afirma que a expectativa de vida está diretamente relacionada com as disparidades na distribuição de renda e ao acesso aos serviços e aos bens necessários para ter uma vida confortável, logo, como é de conhecimento público, a região Nordeste e seu interior sempre sofreram com a pobreza e a fome decorrentes da falta de investimentos em insumos suficientes para as populações pobres, sem contar o outro fator também muito conhecido que é a seca, que na década de 1950 castigou o sertão nordestino ${ }^{6}$.

\footnotetext{
${ }^{6}$ As secas da década de 1950 são apresentadas por Villa (2001) em seu livro "Vida e morte no sertão".
} 
Para se entender melhor o fator econômico em sua influência na familiaridade nordestina em relação à morte, escolhemos utilizar dados da pesquisa de Simões e Oliveira (1984), que estudam em seu artigo exatamente como se deu a evolução da mortalidade na região nordeste entre as décadas de 1940 e 1980, e apresentam dados relevantes que ajudam a compreender como as disparidades econômicas afetam diretamente a vida e a morte do nordestino. Eles utilizam dados do IBGE que apontam que a expectativa de vida no nordeste, predominantemente pobre, em relação às outras regiões do país é em 1940 de 02 a 12 anos a menos, na década de 1950, de 06 e 15 anos, e na década de 1960, de 12 a 19 anos.

Em nosso levantamento preliminar de fontes, não foram localizados documentos que pudessem fornecer dados sobre as condições econômicas das famílias na cidade de Barro, Cariri cearense, e assim, para nossa proposta de pesquisa, a história oral será a fonte que dará meios para apreensão das condições socioeconômicas dessas famílias, uma vez que os relatos orais são uma fonte em potencial para além do estudo da cultura, que é seu lugar mais comum.

Ainda relacionado à questão econômica, Maranhão (1992) afirma que no Nordeste havia, na verdade, um ciclo da morte, no qual as crianças já nascem destinadas à morte prematura. A miséria existente faz com que mesmo ainda no útero a criança inicie sua vida desnutrida, formando-se sem os devidos nutrientes para um ser humano ser considerado saudável. Ao nascer, este processo continua de forma ainda mais 
agressiva $^{7}$. Aquelas que, por condições econômicas, por sorte ou outro motivo conseguem deixar a infância, não a deixam em melhores condições, como apontam os estudos de Simões e Oliveira (1984), pois ainda estão no ciclo da morte antecipada.

Mas como se pode estabelecer uma relação entre a função econômica e as manifestações culturais atingidas por ela? Para aqueles que têm um mínimo de familiaridade com a cultura nordestina, a religiosidade se mostra como um fator de evidenciação da relação dos vivos com a morte, uma vez que as práticas religiosas se mostram mais frequentes nas famílias menos favorecidas economicamente.

A religiosidade do brasileiro há muito se mostra um aspecto relevante dentre suas características, e partindo disso, Chiavenato (1998) afirma que também a superstição é algo culturalmente intrínseco ao nordestino. A morte de crianças, ainda maior que a de adultos como dito acima, para este autor, era diferente da morte de adultos, pois, por serem "anjinhos" inocentes que não chegaram a usar da razão, poderiam ter dois destinos, se morreu batizada, a criança passava pelo purgatório rapidamente e sem sofrimento algum ia para o céu, e se não era batizada, ia para o limbo, nem céu nem inferno, mas lugar neutro, de onde voltava para pedir que fosse batizado.

Com esta mistura de religiosidade e superstição, apreender como a morte era pensada pelo nordestino sertanejo da década de 1950 que perdera um ente querido e como esta mesma mistura influenciou no

${ }^{7}$ Como pôde ser percebido na cidade de Barro a partir da documentação cartorial, o alto índice de morte era entre crianças. 
cotidiano das famílias que sofreram a perda, levam-nos a compreender aspectos de uma cultura regionalizada.

Paulo Henrique Muniz (2006) afirma que as representações estão intrinsecamente ligadas à cultura e aos significados e, por isso deve-se entender a morte como um fenômeno inerente à vida. Para o autor, a morte deve ser pensada em sua relação com os aspectos sociais, culturais e econômicos, que estão em um processo contínuo de mudança através da história humana, pois a morte por ela mesma, isolada destes aspectos, é impossível de nos permitir compreendê-la. E por isso, afirmamos ser a relação dela com o luto e a memória o caminho historiográfico a ser percorrido para melhor analisá-la.

Em seu texto o autor ainda levanta duas questões: "Por que estudar a morte?" e "Como estudar a morte?". As respostas que dá a esses questionamentos parecem muito pertinentes, pois para ele, o porquê de estudar a morte é o fato de trabalhar com memórias, identidades, aspectos culturais e simbólicos de uma determinada sociedade, grupo, comunidade. "A morte deve ser estudada através de suas manifestações socioculturais, símbolos e espaços que as sociedades destinaram a ela" (MUNIZ, 2006: 164).

Para compreender a morte e como o homem encara seu destino final, deve-se obedecer a ritos e lógicas culturais próprias, levando em consideração as questões histórico-temporais e regionais. Deste modo, é partindo disso que o objetivo geral de nossa pesquisa repousará em apreender como a morte era percebida pela população barrense/caririense na década de 1950 e como a memória sobre a morte foi 
construída e mantida, isto é, compreender o relacionamento do sertanejo com a morte na década de 50 .

Pensar essa relação com a morte do outro é pensar sobre o luto, como dito no início deste artigo. Parkes (1998), psiquiatra inglês que estuda as ações humanas frente à morte, afirma em seu livro "Luto: estudos sobre a perda na vida adulta" que este estado emocional e psíquico do ser humano acontece por ser a morte de alguém próximo uma das maiores perdas e grande abalo na vida adulta. Este fenômeno, para o autor, é passível de tratamento médico, uma vez que promove mudanças na vida da pessoa enlutada, como atitudes diferentes das que comumente ela tem, por exemplo, a privação, durante a qual a pessoa que perdeu alguém tende a se isolar demasiadamente, ou mesmo doenças, como a depressão. Para este autor, um dos agravantes do luto é a forma da morte da pessoa querida. Aqui voltamos às causas: fatalidades e desigualdades. Qual poderia ser mais agravante para o luto?

Essa concepção de que a morte de alguém pode trazer mudanças substanciais na vida dos entes que ficam é o cerne da abordagem em uma pesquisa que busca uma compreensão sociocultural e histórica de uma sociedade marcada pela perca frequente de pessoas próximas ou parentes.

Para Ariès (2003), existem duas modalidades de luto, o ritualizado e o exacerbado. Chiavenato (1998) aponta que até meados da década de 1950 no Brasil, o luto frequente é aquele marcado por ações instituídas culturalmente ao lidar com a morte alheia, que por muito tempo foi marcado pelo ato de vestir-se de preto, mostrar mansidão e ficar recluso, 
evitar "alegrias" como forma de respeito à memória do morto, expondo aos demais o sofrimento causado pela morte do ente e, assim permitindo a aproximação das pessoas para confortar. Este seria o luto ritualizado. Já no luto exacerbado, acrescenta-se a estes ritos, o choro desesperado, os males súbitos causados pela perda do ente, e o isolamento.

Até os dias atuais é possível perceber no dia-a-dia do sertão cearense reminiscências da modalidade ritualística de luto, onde as famílias são "proibidas" de ouvir música, de ir a festas, de mostrarem-se felizes e até mesmo de se relacionarem com outras pessoas em casos de morte de cônjuge.

Sendo assim, o luto deve ser pensado como um estado emocional essencial na formulação da memória daqueles que perderam entes por ser nesta etapa do lidar com a morte do outro em que o enlutado fortalece ou mesmo reformula sua concepção sobre o fenômeno, mostrando que a relação entre luto e memória é uma via dupla, onde estudando o luto percebemos o processo de construção da memória e estudando a memória é-nos permitido compreender a significação atribuída a este luto. Assim, temos acesso às características da morte, do luto e de seus significados a partir da memória, e ao pensar a memória e sua relação com temática, a visão de Freitas (2006) se mostra deveras pertinente, já que a autora pensa a memória como a faculdade mental de conservar certas informações, por meio das atividades cerebrais e psíquicas.

Segundo Freitas (2006), a memória é um processo composto não somente pelo ato de reter, mas também de dispensar informações, logo, a memória deve ser pensada como a relação entre o conservar lembran- 
ças e o esquecer delas, ações estas que estão diretamente relacionadas com o contexto social do agente do processo. Ela baseia sua discussão em Maurice Halbwachs, corroborando com a visão dele de que ao invés de tratar a memória isoladamente, deve-se compreendê-la na relação homem-sociedade, uma vez que o ato de lembrar ou esquecer é uma ação coletiva, pois mesmo o indivíduo sendo o detentor da memória, esta memória somente tem respaldo no grupo deste memorizador.

Desta forma, considerar a memória da forma que Freitas (2006) propõe, pensando justamente nessa perspectiva de memória coletiva/social, onde o sertanejo, embora tenha sua individualidade, está inserido num contexto sociocultural que sustenta uma forma de memória específica daquele espaço e tempo, colabora com a possibilidade de se compreender este espaço sociocultural e histórico.

A morte, então, ganha historicidade para o historiador que vê nela significados não naturais, mas construídos através do tempo, que obedecem às características da sociedade estudada, a qual também determina os modos de lidar com este fenômeno, as formas de luto, assim como influencia no processo da memória, que é baseado, como aponta Ouriques (2013), na dialética esquecimento-lembrança.

\section{A memória, o luto, a morte: considerações}

A memória é um elemento essencial do que se costuma chamar identidade, individual ou coletiva, cuja busca é uma das atividades fundamentais dos indivíduos e das sociedades de hoje, na febre e na angústia (LE GOFF, 1990, p.477). 
A memória é uma das principais faculdades humanas formadora do ser e sua mentalidade ao reter apenas informações que encontram respaldo para a vida do indivíduo em relação a seu meio, evidenciando formas determinadas que variam de acordo com o tempo e o local (ARIÈS, 2003). Assim, como afirma Le Goff (1990), a memória e a identidade são indelevelmente inseparáveis, já que a identidade, individual ou coletiva, é construída a partir da memória. Deste modo, não só o próprio indivíduo se constrói a partir das memórias que o envolvem, mas ela é também a ferramenta utilizada para a manutenção e preservação do outro na lembrança daquele que rememora. É assim que os mortos continuam vivos na memória dos que ficam.

Para a preservação dessa memória, existem alguns meios de manter a pessoa que se foi, “viva”. Segundo Chiavenato (1998), um dos modos que vem se tornando comum no Ocidente capitalista, mais especificamente nos Estados Unidos, é o embalsamamento do morto para que seja mantida sua aparência de quando vivo. Mas, como no caso do Brasil, outros meios eram utilizados no século XX, como fotografias do ente $^{8}$, tanto em vida quanto quando já morto, suas roupas e também itens pessoais eram guardados com respeito e carinho, mostrando a especificidade desse espaço cultural.

Focando no meio de preservação da memória através das fotografias, vale concordar com o que Peter Burke (2004) afirma ao dizer que as fotografias e outros tipos de imagem nos permitem compartilhar as

${ }^{8}$ Cf. RIEDL, Titus. Últimas Lembranças: retratos da morte, no Cariri, região do Nordeste Brasileiro. São Paulo: Annablume, Fortaleza: Secult, 2002. 
experiências não verbais e também o conhecimento de culturas passadas, ou seja, nos permitem imaginar o passado de forma mais vívida. Concordamos com ele neste aspecto quanto à afirmação de que "[...] imagens, assim como textos e testemunhos orais, constituem-se numa forma importante de evidência histórica. Elas registram atos de testemunho ocular" (BURKE, 2004: p.17).

Burke (2004) ainda aponta alguns pontos que devem ser levados para a pesquisa, como: as imagens não dão acesso ao mundo social diretamente, mas sim a visões contemporâneas daquele mundo, ou seja, a construção historiográfica por mais que utilize os relatos das experiências das próprias pessoas que perderam um ente, estará sendo construída em um tempo diferente, com visões e valores diferentes. Embora, ele aponta que mesmo sobre essa construção sobre o outro, o testemunho das imagens necessita ser colocado em seu próprio contexto (cultural, político, econômico, material etc.) e, assim como com textos, o historiador precisa ler nas entrelinhas, observando pequenos detalhes despercebidos pelo povo contemporâneo à fonte imagética.

Outro meio de manter a memória do falecido viva é o próprio jazigo, onde a visita, como afirma Ariès (2003), serve como meio de cultivar sua lembrança, pois, ao contrário da Idade Média, onde o morto era entregue aos cuidados da Igreja, a partir dos séculos XIX e XX, quer que se haja um local próprio do morto para que possa ser visitado como se em vida, como se imortal, como se o pudesse encontrar naquele local destinado aos que partiram. 
Deste modo, podemos dizer que o estudo sobre a morte e o luto é um caminho que fornece uma vasta possibilidade de compreensão e análise de um grupo ou sociedade bem determinado no tempo e no espaço, e a memória, então, seria o ponto chave para um trabalho sob essa perspectiva.

Os meios utilizados pelos indivíduos, grupos familiares ou comunidades para manter a memória sobre o ente que se foi, sobre as causas da morte e sobre a lida com essa morte, podem fornecer meios de apreensão que podem ser concatenados com discussões mais amplas sobre a vida destes grupos e comunidades, ou diversas possibilidades de discussões historiográficas, envolvendo não apenas aspectos culturais, mas também sociais e econômicos.

As relações existentes entre as pessoas e como essas relações estão intrínsecas em uma articulação que envolve também fatores econômicos - como é o caso da morte no sertão nordestino durante a década de 1950 - se mostram também a partir da memória, e retomando o que Freitas (2006) afirma, através dela pode-se compreender uma sociedade, compreendendo o processo memorizador dos indivíduos de determinado grupo.

Halbwachs (1990) afirma em seu livro "Memória Coletiva" que um indivíduo não consegue rememorar sozinho todo um período em que esteve envolvido, que viveu, mas é quando ele se situa dentro de um grupo e a partir deste grupo constrói determinada memória, que se torna possível compreender as experiências deste indivíduo e de seu grupo. Assim o autor utiliza o termo "memória coletiva": a memória de um 
indivíduo apoiada em um grupo bem definido. Quando se rompe o grupo, a memória tende a esvair-se.

Por outro lado, Portelli (1997) é contra a utilização do termo "memória coletiva", uma vez que para ele

[...] a memória é um processo individual, que ocorre em um meio social dinâmico, valendo-se de instrumentos socialmente criados e compartilhados. Em vista disso, as recordações podem ser semelhantes, contraditórias ou sobrepostas. Porém, em hipótese alguma, as lembranças de duas pessoas são - assim como as impressões digitais, ou, a bem da verdade, como as vozes - exatamente iguais (PORTELLI, 1997, p.17).

Segundo o autor, mesmo se trabalhando com memórias de indivíduos pertencentes a um grupo, como no de sertanejos que perderam seus entes na década de 1950 no Cariri cearense, é perigoso situar essas memórias fora do indivíduo, retirando a subjetividade do ato memorialístico.

Embora haja um conflito de ideias quanto ao uso de tal termo, ambos corroboram em algo essencial para a pesquisa a que nos propomos realizar: para uma compreensão sociocultural de uma comunidade de indivíduos, é preciso se fazer uso da história oral para apreender as individualidades e as coletividades, encontrar os padrões e modelos de memória que vão além da pessoa, e somente com esta memória, isto é, a história oral, é possível “[...] o esforço de reconstruir padrões e modelos à atenção às variações e transgressões individuais concretas" (PORTELLI, 1997, p. 16). Padrões e modelos estes que seriam, para os estudiosos da morte, os tratos e as lidas para com ela. 
Deste modo, longe de ter como objetivo abarcar toda a discussão acerca do tema que envolve este artigo, esperamos que este texto sirva para mostrar ao leitor/historiador uma nova possibilidade de se compreender o seu objeto de estudo, que é o homem em seu percurso histórico, a partir de algo que, sem dúvida, não foge a nenhuma sociedade: a morte e o envolvimento humano com ela, não apenas no próprio morrer, mas também na morte do outro.

\section{Referências bibliográficas}

ARIÈS, Philippe. História da Morte no Ocidente. Rio de Janeiro: Ediouro, 2003.

BRASIL. MINISTÉRIO DO DESENVOLVIMENTO AGRÁRIO. Plano Territorial de Desenvolvimento Rural Sustentável: Território. Cidadania do Cariri - MDA/SDT/AGROPOLOS. Fortaleza: Instituto Agropolos do Ceará, 2010.

BURKE, Peter. Testemunha Ocular: História e Imagem. Bauru: Edusc, 2004.

CHIAVENATO, Júlio José. A morte: uma abordagem sociocultural. São Paulo: Moderna, 1998.

FEITOSA, Antonio Lucas Cordeiro; QUEIROZ, Silvana Nunes de; CORDEIRO NETO, José Raimundo. Industrialização, Trabalho e Sociabilidade no Espaço Urbano do Triângulo Crajubar-CE. Observatorium: Revista Eletrônica de Geografia, v.1, n.2, p.91-104, jul. 2009. Disponível em:

http://www.observatorium.ig.ufu.br/pdfs/1edicao/n2/INDUSTRIALIZA $\%$ C7\%C3O,\%20TRABALHO $\% 20$ E $\% 20$ SOCIABILIDADE $\% 20 \mathrm{NO} \% 2$ 0ESPA\%C7O\%20URBANO\%20DO\%20TRI\%C2NGULO\%20CRAJU BAR-CE.pdf>. Acesso em: 29/04/2014. 
FREITAS, Sônia Maria de. História oral: possibilidades e procedimentos. 2. ed. São Paulo: Associação Editorial Humanistas, 2006.

HALBWACHS, Maurice. A memória coletiva. São Paulo: Vértice, 1990.

LE GOFF, Jacques. História e Memória. São Paulo: Editora da Unicamp, 1990.

LUIZETTO, Flávio. Reformas religiosas. Contexto: 1989.

MARANHÃO, José Luiz de Souza. O que é morte. 4. ed. São Paulo: Brasiliense, 1992.

MUNIZ, Paulo Henrique. O estudo da morte e suas representações socioculturais, simbólicas e espaciais. Revista Varia Scientia, Cascavel, v. 06, n. 12, p. 159-169, 2006. Disponível em: < http://erevista.unioeste.br/index.php/variascientia/article/viewArticle/1520>.

Acesso: 29/04/2014.

OURIQUES, André Luiz Almeida. Esquecimento e História: um medo indelével ou uma possibilidade epistemológica? In: ARANHA, Gervácio Batista; FARIAS, Elton John da Silva. Epistemologia, Historiografia e Linguagens. Campina Grande: EDUFCG, 2013, p. 84-104.

PARKES, Colin Murray. Luto: estudos sobre a perda na vida adulta. São Paulo: Summus, 1998.

PORTELLI, Alexandre. Tentando aprender um pouquinho: algumas reflexões sobre a ética na História Oral. Revista Projeto História, São Paulo, v. 15, abril de 1997.

SIMÕES, Celso Cardoso da Silva; OLIVEIRA, Luiz Antonio Pinto de. Região Nordeste: a evolução da mortalidade e seus determinantes. In: Encontro Nacional De Estudos Populacionais, 4, 1984, Anais... - Volume 4, 1984, p. 2093-2111.

TOLKIEN, J. R. R. O Silmarillion. 4. ed. São Paulo: Martins Fontes, 2009.

UM CORPO subterrâneo. Douglas Machado. Teresina: Trinca Filmes, 2007. Documentário online (52 min), son., color. 